\title{
Orbiter Boundary Layer Transition Prediction Tool Enhancements
}

\author{
By \\ Scott A. Berry", Rudolph A. King ${ }^{\dagger}$, Michael A. Kegerise ${ }^{\dagger}$, William A. Wood ${ }^{\ddagger}$, \\ Catherine B. McGinley ${ }^{\S}$, Karen T. Berger ${ }^{\ddagger}$ \\ NASA Langley Research Center, Hampton, VA 23681 \\ And \\ Brian P. Anderson ${ }^{*}$ \\ NASA Johnson Space Center, Houston, TX
}

\begin{abstract}
Updates to an analytic tool developed for Shuttle support to predict the onset of boundary layer transition resulting from thermal protection system damage or repair are presented. The boundary layer transition tool is part of a suite of tools that analyze the local aerothermodynamic environment to enable informed disposition of damage for making recommendations to fly as is or to repair. Using mission specific trajectory information and details of each damage site or repair, the expected time (and thus Mach number) of transition onset is predicted to help define proper environments for use in subsequent thermal and stress analysis of the thermal protection system and structure. The boundary layer transition criteria utilized within the tool were updated based on new local boundary layer properties obtained from high fidelity computational solutions. Also, new ground-based measurements were obtained to allow for a wider parametric variation with both protuberances and cavities and then the resulting correlations were calibrated against updated flight data. The end result is to provide correlations that allow increased confidence with the resulting transition predictions. Recently, a new approach was adopted to remove conservatism in terms of sustained turbulence along the wing leading edge. Finally, some of the newer flight data are also discussed in terms of how these results reflect back on the updated correlations.
\end{abstract}

\section{Nomenclature}

$\begin{array}{ll}\mathrm{Re}_{\theta} & \text { momentum thickness Reynolds number } \\ M_{e} & \text { edge Mach number } \\ k & \text { trip or protuberance height (in) } \\ \delta & \text { boundary layer thickness (in) } \\ \mathrm{L} & \text { cavity length (in) } \\ D & \text { cavity depth (in) } \\ \mathrm{H}_{e} & \text { enthalpy at boundary layer edge } \\ \mathrm{H}_{w} & \text { enthalpy at the wall } \\ \mathrm{C} & \text { correlation coefficient } \\ \mathrm{m} & \text { protuberance correlation power }\end{array}$

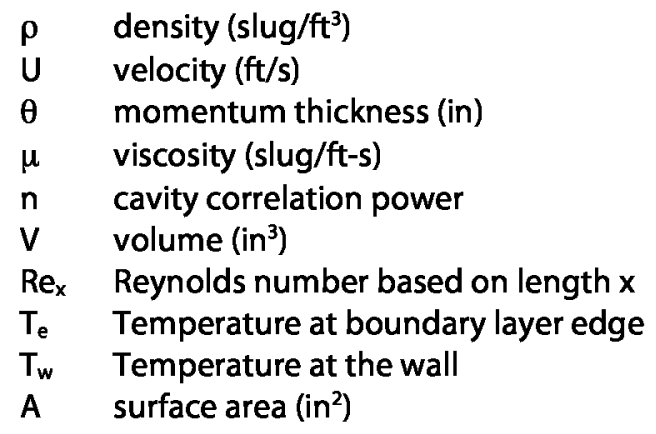

\section{Introduction}

As a testament to NASA's commitment to safety, a new damage assessment process was formulated after the completion of Columbia's accident investigation' to insure the thermal protection system (TPS) on each and every Shuttle mission is healthy prior to entry into the earth's atmosphere. This commitment to safeguard the nations astronauts and space-access capability represents a significant investment of time and effort by NASA, both in terms of the up-front development costs (multiple years and hundreds of personnel), as well as through continued implementation and refinement with every

\footnotetext{
* Research Scientist, Aerothermodynamics Branch, MS 408A, AIAA Associate Fellow.

${ }^{+}$Research Scientist, Flow Physics and Control Branch, MS 170.

‡ Research Scientist, Aerothermodynamics Branch, MS 408A, AIAA Senior Member.

${ }_{5}^{5}$ Assistant Branch Head, Flow Physics and Control Branch, MS 170, AIAA Member.

** Aerospace Engineer, Applied Aeroscience and CFD Branch, M/S EG3, AIAA member.
} 
mission. The damage assessment process begins for each mission soon after getting detailed photographic documentation sent down from astronauts on the Space Station showing the state of the TPS (see Figure 1 which provides a typical photograph taken during STS-114). These high resolution photographs are taken early in the mission, typically on flight day 2 or 3 , as the vehicle pauses a safe distance from the station and does a slow pitch over (allowing myriad views and lighting conditions) called the rendezvous pitch maneuver (RPM). Once the damage assessment team (DAT) gets the RPM

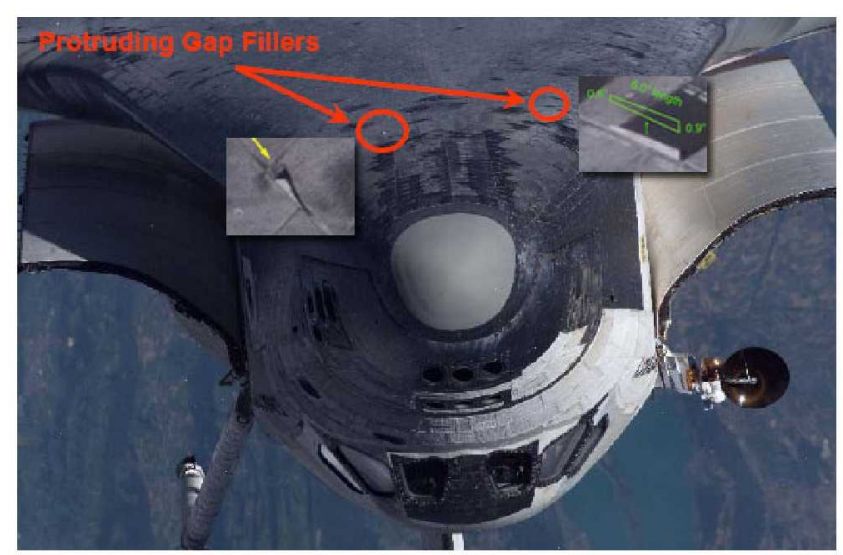

Figure 1. RPM photograph of the Shuttle taken from space station used to identify TPS damage during STS-114 photographs on the ground, each identified damage site, whether a gouge or cavity in TPS or a protrusion of the gap fillers from between the tiles, is catalogued and assessed. If needed, a focused inspection can be requested whereby the onboard laser scanner on the end of the boom can be used to obtain detailed three-dimensional data of the damage. The process of analyzing and reviewing all the damage sites typically takes another 2 to 3 days to complete and doing this early in the mission assures the mission management team (MMT) that the primary mission objectives can proceed unimpeded.

The damage assessment process integrates tools and analysis from diverse disciplines within the Orbiter project, such as structures \& materials, thermal, and aerodynamics, to provide an evaluation of whether the TPS is healthy enough for reentry based on any and all damage sites identified during onorbit inspections. ${ }^{2}$ This assessment team has the capability to recommend repairs if the damage is deemed severe enough, although a repair has not been requested on any mission other than during STS-114 when an astronaut attached to the end of the boom removed two protruding gap fillers by hand. ${ }^{3}$ Figure 2 provides a flowchart of the damage assessment process, showing the primary inputs and outputs, as well as the specific tools that are utilized. The inputs include the reentry trajectory, which is used to extract pertinent data from the computational fluid dynamics (CFD) solution database, and details regarding the damage site locations and geometry. Tools were developed for the analysis process to analyze boundary layer transition (BLT), cavity heating, and TPS response. The primary outputs include TPS material temperatures, bond-line factors-of-safety (FOS), and structural margins-ofsafety (MOS) and out-of-plane-deflections (OOPD) in the vicinity of the damage sites. The BLT Tool, one of the first tools in the process, predicts the onset of hypersonic BLT on the Orbiter windward surface, thus establishing a more accurate aeroheating environment for use with subsequent analyses. The BLT and turbulent wedge tools are run simultaneously, providing the onset time prediction for each damage site and the downstream spatial influence associated with each predicted transition time. The heritage body point heating code from Rockwell/Boeing, XF0002, provides the framework around which all the new DAT tools perform.

The BLT tool was first reported in Ref. 4 , along with details about the ground-based data, ${ }^{5}$ computational approach, ${ }^{6}$ and flight results ${ }^{7}$ used to derive the first version of the tool. As mentioned, the BLT Tool calculates the expected time of boundary layer transition

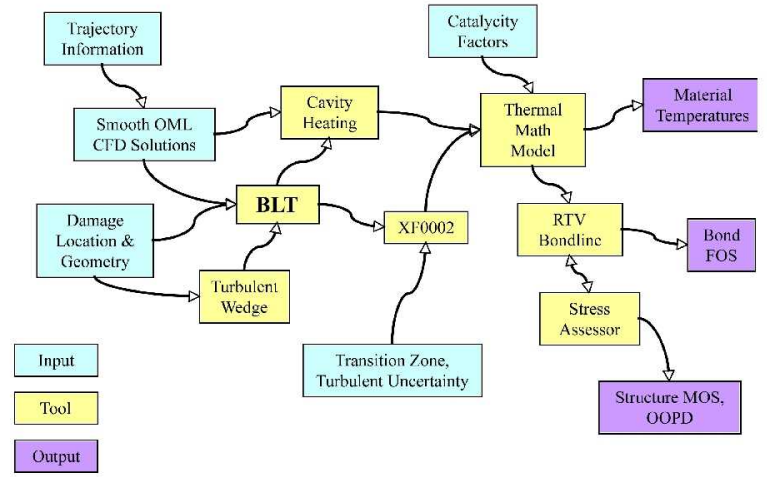

Figure 2. Shuttle Orbiter damage assessment process after on-orbit inspection 
during entry based on observed damage and/or repair locations and geometries. The BLT Tool requires mission specific entry trajectory information (altitude, velocity, angle of attack, air density, air temperature, etc.) as input. The tool includes a database of computed boundary layer parameters that cover a range of nominal trajectories for entry and utilizes an interpolation tool to extract specific local properties used to determine the boundary layer state during the mission specific trajectory. The source code is written in Fortran and can be quickly run on most computer systems. The BLT prediction methodology was established and developed based on simplified tripping elements (protuberances and cavities) on scaled wind tunnel models. A database of computational solutions at wind tunnel and flight conditions was generated to develop and apply the BLT correlation. Calibration of the BLT Tool had been carried out by comparison of predicted transition results to several historical high Mach number flight cases. Recently, this tool has been updated to provide greater confidence in the predicted results. The present paper provides an overview of this effort to develop Version 2 (V2) of the BLT Tool that is now used in support of the Orbiter on-orbit damage assessment process. Also, details are provided regarding a recent effort to define a methodology for reducing conservatism along the wing leading edge. This paper should be viewed as a companion to several papers detailing a flight experiment that has recently flown on two missions to gather new boundary layer flight data (see Ref. 8 and 9), as well as the off-board infrared imaging campaign called HYTHIRM that has been on-going in support of Shuttle. ${ }^{10}$ Some of the results from these separate efforts will be further discussed towards the end of this paper.

\section{BLT Tool V1}

The first version of the BLT Tool was implemented, after a year and a half of development effort, in time for the first Return to Flight (RTF) mission, STS-114. Considering the resource constraints and scope for this highly integrated and multi-disciplinary effort, some simplifying choices were implemented early in the development of BLT Tool V1. For instance, previous studies ${ }^{11-13}$ had investigated BLT correlations using wind tunnel data in combination with boundary layer edge conditions from an engineering code called $\mathrm{LATCH}_{,}{ }^{14}$ which provided confidence that a useable correlation could be developed in time for flight application. This provided the starting point for the first version of the BLT Tool and was instrumental in allowing the task group to focus primarily on acquiring new Shuttle specific data on protuberances, cavities, and ablation (for possible repair scenarios), populating a simpler computational database, and reviewing the existing flight data. Without a target correlation approach in hand, it was quite likely that meeting the goal of implementing a tool in time for the first RTF mission might not have been accomplished. However, the first use of this tool during STS-114 revealed some concerns with understanding the uncertainties of the correlations outside the bounds of both the computational approach adopted, as well as the existing flight calibrations data. The LATCH database was only thought to be appropriate up to Mach 20, while the flight data only provided BLT calibration data for Mach numbers between 6 and 18. The two protruding gap filler cases on STS-114 had BLT onset predicted much earlier than Mach 20, which highlighted the need to better understand uncertainties at extrapolated conditions and led to the request for higher fidelity flight data based on a controlled boundary layer experiment on the Shuttle. ${ }^{8}$

\section{Hypersonic BLT}

A crucial issue for the design of reentry vehicles is knowing when the boundary layer will transition from laminar to turbulent, resulting in a significant increase in the convective heat transfer rate to the surface (perhaps over four times higher). All reentering spacecraft require a TPS in order to withstand extreme post-shock temperatures and surface shear stresses that result from hypersonic velocities within the atmosphere. Luckily, a boundary of fluid envelops the vehicle and acts as a buffer, reducing the postshock conditions to more manageable levels near the surface. Initially this "boundary layer" starts out as laminar, which can be thought of as orderly layers, or laminates, of fluid. Eventually the increasing atmospheric density and/or the vehicle surface roughness induces chaotic mixing of the layers, or turbulence, which contributes to increased convection of energy to the surface. To circumvent the issue of having an accurate method for prediction of transition, TPS designers have in the past typically adopted conservative approaches, such as using an all-turbulent heating profile to select material and size thickness. This approach was utilized for the X-34 design ${ }^{15}$ and more recently for the Crew 
Exploration Vehicle (CEV). ${ }^{16}$ Having an accurate BLT prediction methodology could lead to decreased conservatism in design of future space flight programs.

Significant progress has been made in recent years to understand the physical mechanisms of the hypersonic boundary layer transition process, which can be characterized by understanding the stability of wave propagations within the laminar boundary layer. Waves develop from perturbations to the orderly layers of fluid, and these initially small disturbances grow or damp depending on the local stability of the wave motion. Semi-empirical predictive methods have been available for years for simple problems with linear processes, but recent advancements are now addressing the non-linear breakdown processes on three-dimensional geometries. Even with these advancements in a theoretical basis for predicting boundary layer transition, implementation of these methods into a useful tool for real time Shuttle mission support are still a long way off due to the complexity of the problem. At present the extensive computational database for the Shuttle is populated with only smooth surface solutions and any attempt to understand the instability process on the Shuttle would have to account for surface roughness effects.

Most, if not all, flight vehicles have surface features that can be characterized as significant roughness and thus provides a by-pass mechanism to the smooth wall transition process. Thus, surface roughness, as dictated by the state of the TPS, plays an integral role in determining the probable transition onset time during reentry. Roughness can be divided into two categories, distributed and discrete. Distributed roughness is characteristically small and abundant, and is usually inherent to the TPS. Discrete roughness is typically inadvertent. It is much larger in scale than distributed roughness and is isolated or infrequent. Most spacecraft designed for reentry have some form of inherent distributed surface roughness. On Shuttle Orbiters, the distributed roughness is due to the (slight misalignments of steps and gaps between the many ceramic TPS tiles. In the case of TPS designed for planetary entry or lunar return, distributed roughness can be formed on the surface during entry by spallation and/or ablation due to extremely high surface temperatures. Traditional ceramic-based TPS tiles such as those used on the Orbiters are also susceptible to inadvertent (discrete) roughness such as damage from launch in the form of cavities and/or gap filler protrusions. For the Space Shuttle Orbiters, the background distributed roughness (tile-to-tile steps and gaps) that in the absence of any large discrete trips will induce boundary layer transition at a Mach number on the order of 8 . On two occasions (STS28 and 73) the Orbiters experienced early boundary layer transition at Mach numbers nearer to 18 due to a discrete roughness as a result of large protruding gap filler.

\section{Shuttle BLT}

Orbiter reentries represent the most comprehensive dataset of available flight boundary layer transition results with over 125 missions to date providing a good statistical reference with which to reveal the complexity of the problem. BLT onset varies with every mission based primarily on the surface roughness characteristics that are highly dependent upon the state of the TPS determined after launch. This complicates the analysis of this flight data as the roughness characteristics prior to entry are typically not known, nor is it controlled in any way during entry. Another complicating factor is the lack of detailed information on the as-flown surface condition that's been recorded after each flight. Even with these shortcomings, the Shuttle data is a valuable dataset with which to better understand the hypersonic BLT problem. While much of the specific data from each of these missions are not available to the general public, a great deal of the boundary layer transition results have been reviewed and summarized over the years. One of the first reports to provide details regarding BLT results from the first few missions was by Lee and Harthun ${ }^{17}$ and was quickly followed by Goodrich, et $\mathrm{al}^{18}$ which provided an initial attempt to look at simple engineering type correlations. Poll ${ }^{19}$ provided a different approach to developing a useful correlation from the Shuttle flight data. This approach was specific to attachment line transition and will be discussed further in a subsequent section. Later, Hartung and Throckmorton ${ }^{20}$ provided a detailed analysis of the first five flights showing the global movement of BLT during entry. In the early $90^{\prime}$ s, Bouslog, et al ${ }^{21}$ provided a BLT summary of first 32 flights, which was then later updated..$^{22}$ More recently, McGinley, et al ${ }^{7}$ provided an in-depth review of all available sources for Shuttle BLT data from the first $\mathbf{1 0 0}$ or so flights. Some more recent flight data and results have also been published by Berry, et al.,23,24 


\section{Methodology for Updating Version 1}

BLT Tool V1 was based on a boundary layer engineering code (LATCH) that supplied both the wind tunnel and flight solution databases for developing and applying the correlations. The final V1 protuberance correlation adopted for mission support used a conservative capture of the best historical flight cases and Mach 6 wind tunnel data using $R_{8} / M_{e}$ and $k / \delta$, as shown in Fig. 3. The final V1 protuberance correlation constant of 27 was based on a bounding line (red dashed) of the flight and Mach 6 data. As the V1 recommendations were being formulated, the BLT Team recognized that a correlation, if based on all the existing wind tunnel data (which would include data from the LaRC Mach 10 and CF4 tunnels), provided insufficient data collapse and would provide predictions too conservative for flight application. Thus only the flight and Mach 6 data were used in the final V1 protuberance correlation developed for flight. A peer review of the data and recommended approach was held prior to finalizing the tool for use during STS-114 and this issue was noted as one that needed to be addressed as soon as possible.

The V1 cavity correlation adopted for mission support was less a correlation and more a threshold line based on a conservative capture of the historical cavity flight cases and Mach 6 wind tunnel data using $\operatorname{Re}_{\theta} / \mathrm{M}_{\mathrm{e}}$ and either $\mathrm{L} / \delta$ or $\mathrm{D} / \delta$, as shown in Fig. 4. Within the time constraints for development of $\mathrm{V} 1 \mathrm{a}$

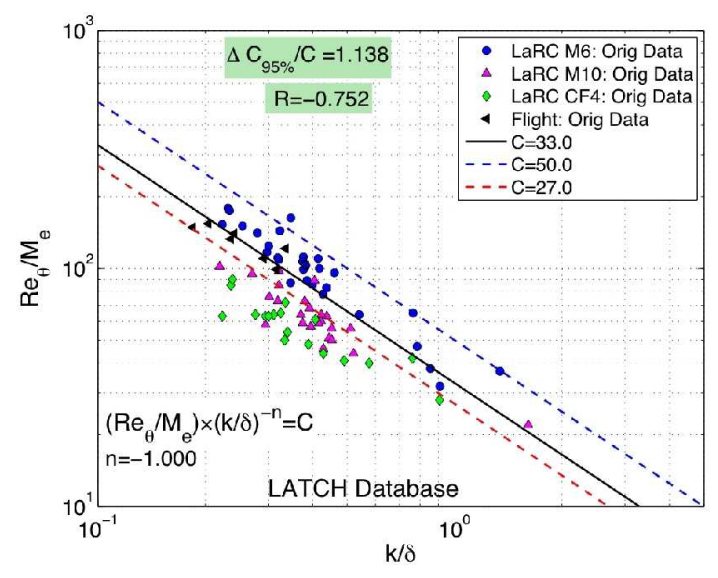

Figure 3. Protuberance correlation utilized for BLT Tool V1 true cavity correlation could not be identified, as shown by the data scatter. For V1, the individual cavity dimensions (length and depth) were substituted in and out of a protuberance-like correlation. The final V1 cavity threshold constants of 100 and 900 for depth and length, respectively, represented conservative threshold lines for flight and Mach 6 data. As the $\mathrm{V} 1$ recommendations were being formulated, the BLT Team recognized that threshold lines, if based on all the existing wind tunnel data (which would include data from the LaRC Mach 10 and CF4 tunnels), provided too conservative an answer for flight application. So in a similar fashion to the protuberance case, the flight and Mach 6 wind tunnel data were the primary driver of the final recommended cavity "correlations".

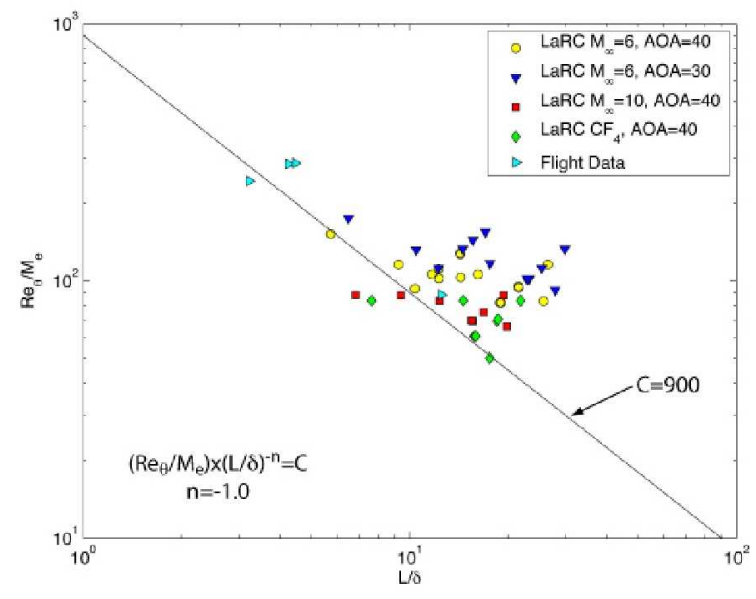

a) Length based cavity correlation

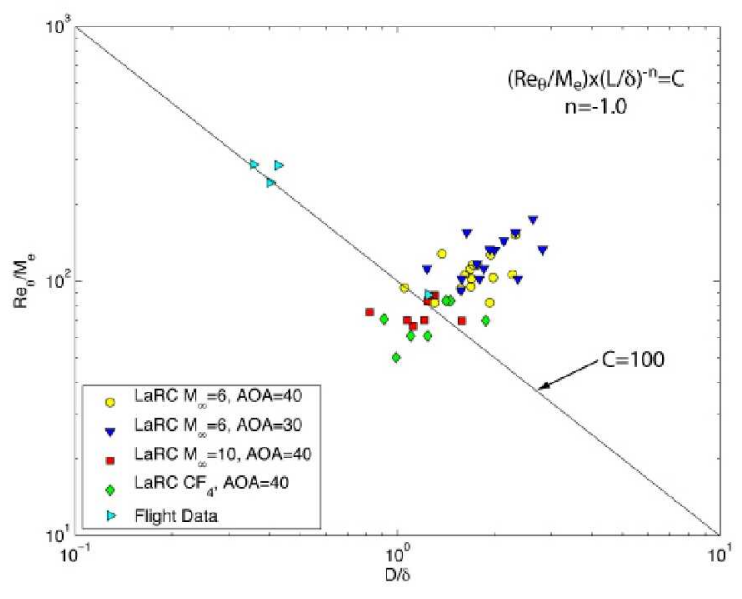

b) Depth based cavity correlation

Figure 4. Final cavity correlations adopted for BLTTool V1 
Version 2 of the BLT Tool has incorporated many enhancements that had been identified as issues either by the original peer review or during STS-114. The specific improvements include an updated wind tunnel database that include additional variables not previously tested, the migration to correlations developed from local boundary layer properties from a Navier-Stokes (N-S) CFD solutions, and finally a more in-depth review of Shuttle flight BLT data, all of which will be discussed in greater detail in the results section. As part of the enhanced wind tunnel data, new tests were conducted in LaRC and CUBRC LENS facilities that included nearly 500 runs in 81 occupancy days in 3 different tunnels. In these wind tunnel entries, as with the previous database, surface heat transfer was the consistent method used to infer the movement of transition. Specifically for the protuberance database, tests were conducted in the LaRC 20-In Mach 6 and LENS Mach 10 and 16 tunnels to investigate various locations, heights, shapes, and orientations along the centerline and attachment line. For the cavity database, tests were conducted in the LaRC 20-In Mach 6 and 10 and LENS Mach 10 and 16 tunnels to investigate various cavity geometries, shapes, orientations, and locations along the centerline and attachment line. The new data was combined with the existing results from the V1 development and then compared against the extracted local properties from the CFD database to develop BLT correlations. These correlations were then compared against updated calibration cases from the in-depth review of the flight data.

Facilities

\section{LaRCTunnels}

Aerothermal testing has been conducted in support of Shuttle at NASA Langley Research Center (LaRC) in Hampton, Virginia in the 20-Inch Mach 6 Air, the 31-Inch Mach 10 Air, and 20-In Mach $6 \mathrm{CF}_{4}$ tunnels. These facilities are conventional blow-down tunnels that utilize dried, heated, and filtered air or $\mathrm{CF}_{4}$ as the test gas. Typical aerothermal test techniques that are utilized in these tunnels are thermocouples, thin-film, thin-skin, schlieren, oil-flow, and phosphor thermography, which is used to provide quantitative global temperature and, thus, heat transfer images. Detailed descriptions of these facilities, along with their associated instrumentation and test techniques can be found in Ref 25 and 26 . Typical operating conditions for the LaRC 20-Inch Mach 6 Air Tunnel are stagnation pressures ranging from 30 to 500 psia, stagnation temperatures from 410 to $500^{\circ} \mathrm{F}$, and free stream unit Reynolds numbers of 0.5 to $7.8 \times 10^{6} / \mathrm{ft}$. A two-dimensional, contoured nozzle is used to provide a nominal freestream Mach number of 6. Typical operating conditions for the LaRC 31-Inch Mach 10 Air Tunnel are stagnation pressures ranging from 350 to $1450 \mathrm{psia}$ and a stagnation temperature on the order of $1350^{\circ} \mathrm{F}$, which yields freestream unit Reynolds numbers of $0.5 \times 10^{6} / \mathrm{ft}$ to $2.2 \times 10^{6} / \mathrm{ft}$. The tunnel has a closed 31 - by $31-$ in. test section with a contoured three-dimensional water-cooled nozzle to provide a nominal Mach number of 10. Typical operating conditions for the LaRC 20-Inch Mach $6 \mathrm{CF}_{4}$ Tunnel are stagnation pressures ranging from 90 to 1940 psia and a stagnation temperature on the order of $700^{\circ} \mathrm{F}$, which yields freestream unit Reynolds numbers of $0.05 \times 10^{6} / \mathrm{ft}$ to $0.7 \times 10^{6} / \mathrm{ft}$. The $\mathrm{CF}_{4}$ tunnel is an open-jet facility.

\section{CUBRC LENSI}

The MH-13 test program ${ }^{27}$ was conducted in the Calspan-University of Buffalo Research Center (CUBRC) Large Energy National Shock (LENS) I facility. LENS I was constructed with the capability to fully duplicate flight conditions at Mach numbers ranging from 7 to 16 and to conduct testing with full-scale versions of missile interceptors and scramjet engines. The major components of the LENS I facility include a 25.5 -foot long by 11 -inch diameter electrically heated driver tube, a double diaphragm assembly, a 60 -foot by 8 -inch diameter driven tube, a fast acting center body valve assembly, multiple nozzles to achieve the desired Mach numbers, and a test section capable of accommodating models up to 3 feet in diameter and 12 feet long. The high-pressure driver section of LENS I has the capacity to operate at 30,000 psi using heated driver gases of hydrogen, helium, nitrogen or any combination of the three. The driver gases can be heated up to $750^{\circ} \mathrm{F}$ and the amount of each gas varied to achieve tailored interface operations for maximum test times. The driven tube can use air, nitrogen, carbon dioxide, helium, hydrogen or any other gases or combinations of gases for model testing. Further discussions of LENS facility capabilities can be found in Ref. 28. 


\section{Computational method}

As mentioned earlier, the conversion to an all CFD solution database was a major element of the BLT Tool V2 effort. An initial investigation into the conversion process, which helped to determine the best course forward, is provided in Ref. 29. New N-S solutions were primarily required for the wind tunnel cases (see Ref. 30 and 31) as many of the flight solutions had previously been completed in support of the cavity-heating tool. ${ }^{32}$ Figure 5 provides a comparison of typical Shuttle entry trajectories in reference to specific flight solution cases. There are on the order of 80 total CFD solution cases, half of which are utilized with the BLT Tool database. A new property extraction tool (details provided in Ref. 33 and 34) was developed for V2 in order to probe and obtain local properties within the boundary layer, in addition to extracting edge conditions. As before, this property extraction tool also had to interpolate spatially on the vehicle and temporally between individual trajectory database points, as well as extrapolate to match Reynolds number.

\section{Flight data}

A cursory review of the flight data was conducted for $\mathrm{V} 1$ due to time and resources constraints. Only readily available documentation had been examined and transition onset times for each mission were taken at face value from existing tables of results compiled years before. Also, the turbulent wedge tool was not available at the time, and thus the link between an identified trip and the onset measurement was at best speculative. For the second attempt, a more thorough investigation of the flight database was conducted, providing a much more focused activity to quantify for $\mathrm{V} 2$ the amount of uncertainty associated with each flight case and to firmly establish a direct linkage between specific damage sites (cause) and the measured transition onset time downstream of each site (effect).

The V2 review of the historical flight cases included a more in-depth examination of the various sources of documentation within the Shuttle program. For instance, while the V1 review was primarily based on documents like the Post-Flight TPS Reports and the Quick Look Runway Reports, the V2 review examined Debris Ice Team Reports and obtained access to the computerized tracking system for TPS problem resolution. Comparisons of the various sources of information provided a measure of uncertainty associated with the fidelity used by the different post-flight ground crews in recording the damage dimensions after each flight. Also, the V2 review acquired the thermocouple data from each flight to insure the measured transition onset times were consistently and correctly identified for each case. The turbulent wedge tool was used to firmly establish the influence of each damage site on the downstream thermocouples, thus helping to link the cause (damage) and effect (BLT onset time) for each calibration case. This new, more in-depth review was instrumental in removing ambiguity in regards to some of the calibration cases. For instance, the V2 review identified small gap fillers that previously had not been accounted for in the vicinity of the cavity sites, thus reducing confidence with several cases used during the $\mathrm{V} 1$ analysis.

Figure 6 provides an example, using STS-28,

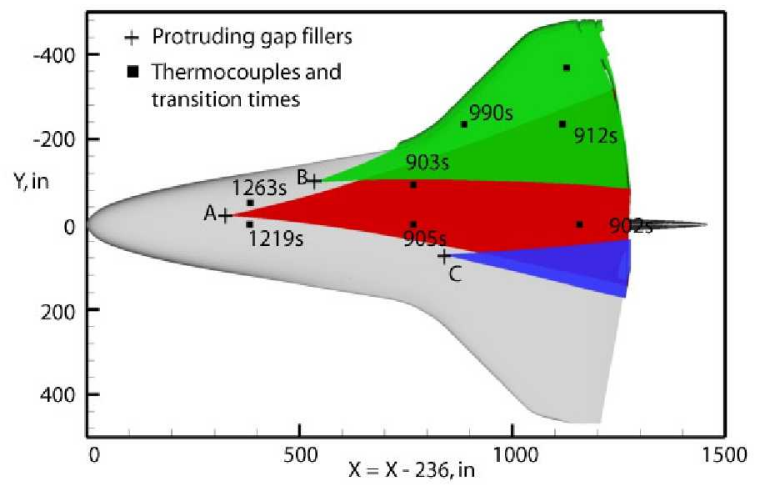

Figure 6. Historical BLT assessment for STS-28 
of the V2 analysis of the historical BLT data. The review of all the post-flight documentation for STS-28 found 10 protruding gap fillers and 27 cavities with dimensions greater than 1 -in. All damage sites were assessed, but only the three gap fillers identified in the figure as sites A-C were determined to have been the probable cause for the measured transition onset times indicated next to each surface thermocouple location. Each gap filler location is modeled with the wedge tool to provide regions of influence of the resulting turbulent flow. The wedge tool for this analysis assumed a turbulent spreading angle of 7.5-deg. In this particular case, only one gap filler (site A) is in a position to have any influence on the most rearward centerline thermocouple measurement. Thus, a gap filler of height 0.5in at location $A$ is the primary candidate responsible for the measured transition onset time of $902 \mathrm{~s}$. Ref. 35 provides further details associated with the extensive flight data review.

\section{Flight support tool development}

As part of the process to mature a second version of the tool for approval by the Orbiter project, a peer review was conducted, which was then followed by an extensive verification and validation (V\&V) assessment. These final steps were necessary to convince the project that proper due diligence had been conducted and that the tool was as good as it could be. A peer review had been conducted during the development of the first version of the tool, and this same group, with a couple substitutions due to scheduling conflicts, was used for this review. A multi-day presentation of task definition, approach, and results was conducted, followed by an intensive Q\&A session, which ultimately led to a final set of written issues and recommendations that were provided for disposition. The peer review group also was instrumental in refining the requirements that fed into the final V\&V process. In all, $\mathbf{5 8}$ separate requirements were identified that eventually needed to be verified and validated with both the wind tunnel and CFD databases, as well as with the final correlations and tool performance. In the experimental arena, there were requirements to assess shape effects, to expand on the parametric variation in testing, and to test in new facilities and at higher Mach numbers than before. On the computational side, there were requirements to assess the quality of the solutions within the database, to verify the accuracy of the boundary layer probe and scaling codes, and to estimate final tool accuracy and performance. For integrated tool performance, requirements were identified to provide a primary and secondary correlation to allow some measure of prediction uncertainty and to exploit a statistical basis for developing confidence factors with the final correlations. One overriding requirement was the desire for V2 of the tool to not be any worse than the predictions from V1 against the historical calibration cases. Details of the V\&V results associated with BLT Tool V2 can be found in Ref. 36. A separate document (Ref. 37 ) provides the details of the extensive V\&V activity associated with the CFD database and extrapolation tool.

\section{Results and Discussion}

A significant effort has resulted in BLT Tool V2 that is used in support of the Orbiter on-orbit damage assessment process. The V 2 effort has provided updated protuberance and cavity correlations. In each case, numerous correlations were investigated before bringing forward final recommendations for primary and secondary correlations for both protuberances and cavities. As part of this V2 effort, a statistical basis for maturing the various correlations was incorporated. A regression analysis was used throughout to establish upper and lower limits that represent the $95 \%$ confidence intervals of each respective dataset. In the discussion to follow, the "best fit" represents the mean of the data, while the lower bound ( $-95 \%$ line) represents a conservative capture of the data trends. Although many correlation approaches were investigated, only the recommended correlations will be presented below. For more details on the extensive list of correlations investigated, please see Ref. 38 for protuberances and Ref. 39 for cavities. Also, a review of recent work to define a new methodology for reducing conservatism in terms of determining when sustained turbulence is expected along the wing leading edge $^{40}$ is presented. The final section will provide some of the most recent flight results.

\section{Protuberance correlations}

The $\mathrm{V} 2$ conversion from LATCH to the N-S derived database provided an immediate benefit of reducing the differences in the correlation trends between the three LaRC facilities. Figure 7 provides a 
comparison of the existing V1 data to the newly acquired V2 data from LaRC Mach 6 and CUBRC LENS (Mach 10 and 16) facilities, using a similar set of correlating parameters (same as before plus an enthalpy ratio term), but now based solely on the $\mathrm{N}-\mathrm{S}$ solutions. The individual facility trends (shown by the different color symbols) are now much closer together, and thus all the experimental data can be included as part of the correlation dataset for V2. The enthalpy ratio term was included for V2 in an attempt to bring the flight trends closer towards the mean value for the experimental dataset. The best fit and bounding lines shown are for the ensemble of all the experimental plus flight data. Note that there are four (appears as three) LENS Mach 16 data points that fall outside the bounds of the rest of the experimental data. These high Mach number data points may be the first indication of the breakdown of the edge property-based correlation for very large trips

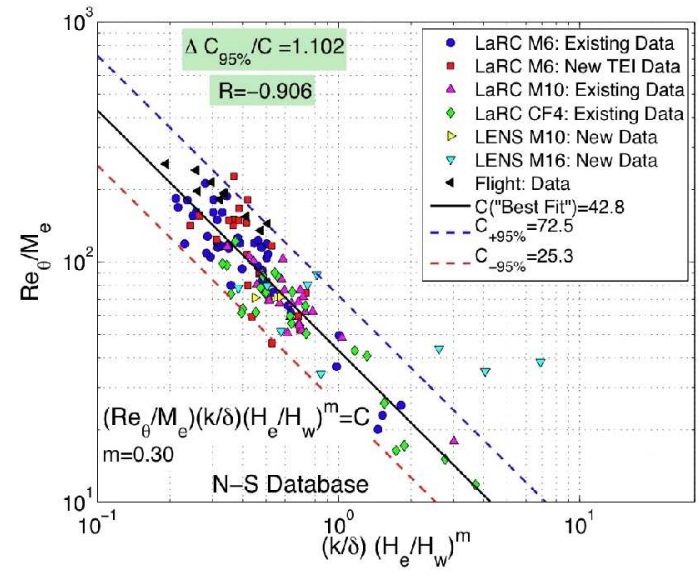

Figure 7. Initial proposed primary protuberance correlation for BLTTool V2

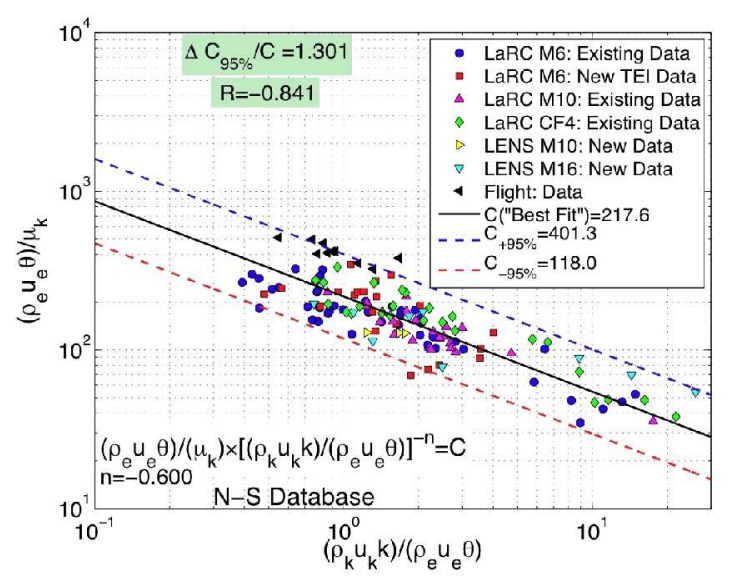

Figure 8. Initial proposed secondary protuberance correlation for BLTTOolV2

Another benefit with the use of N-S solutions for V2 is that information within the boundary layer is now available for investigating an alternate correlation approach based on $\mathbf{R e}_{k}$. Figure 8 provides the same transition onset data now plotted using local properties both within the boundary layer and at the edge. The ideal correlation for this approach, according to Ref. 41 , is a correlation curve with a minus one slope, which would thus provide $\mathrm{Re}_{\mathrm{k}}$ equal to a constant. The present data does not support this trend; in fact the data suggests a curve coefficient with a -0.6 slope. While not consistent with Ref. 41 , this correlation still provides a useable alternate approach that now captures the previously mentioned LENS Mach 16 outlier data points within the bounds of the experimental data.

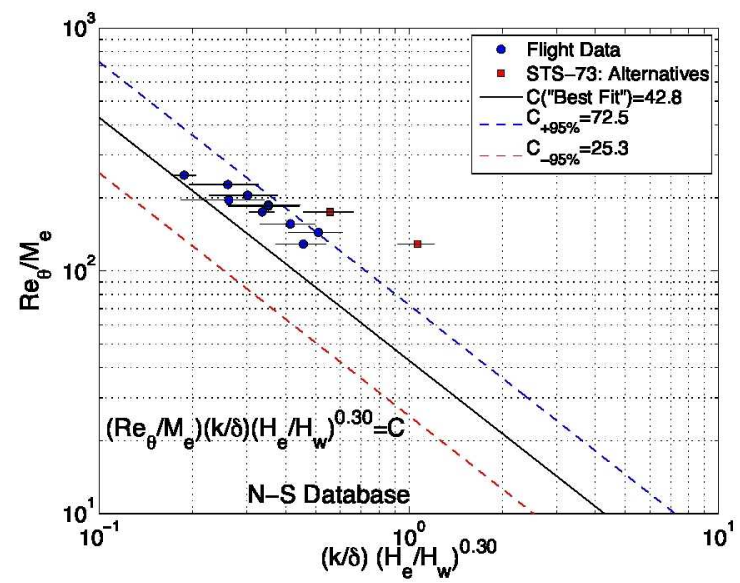

a) $\operatorname{Re}_{\theta} / M_{e}$ correlation

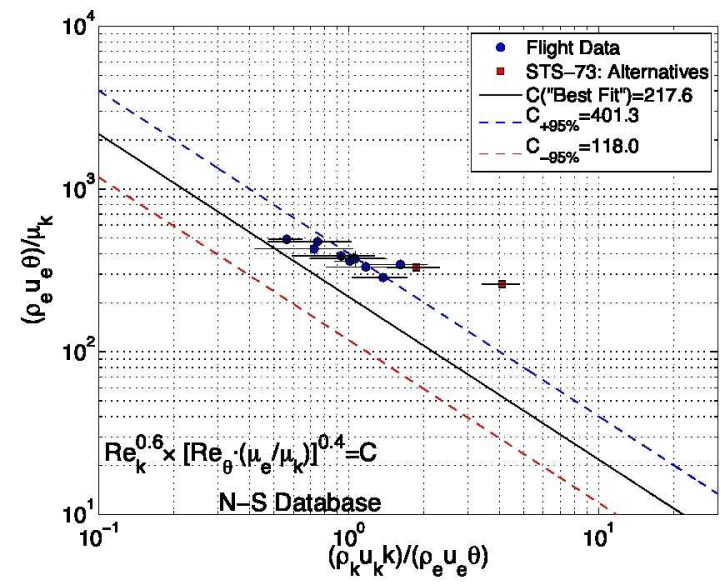

b) Re $_{\mathrm{k}}$ correlation

Figure 9. Flight uncertainties in relation to bounds of experimental and flight data 
The results shown in Figs. 7 and 8 were part of the initial set of correlations presented during the peer panel review. A discriminating eye can observe that the historical flight cases are biased towards the upper bound of the ensemble (ground-based and flight) spread for both correlation approaches. Per a recommendation from the Peer Review, Fig. 9 provides a replication of the two previous plots, but now with the wind tunnel data points removed and the addition of uncertainty bars on the flight data. The flight uncertainty bars shown in the figure are based on the noted uncertainty from Ref. 35 of the gap filler protrusion heights and does not account for the uncertainty with how or when any noted gap filler bending may have occurred. The STS-73 case, in particular, was identified to have a large bend in the gap filler upon inspection on the ground. The documented runway protrusion height was 0.6 -in bentover, while noted that when straightened the protrusion height was 1.4-in. Alternate interpretations of these two heights at different times of indicated transition onset are shown on the figures. Again, note that on both plots the flight data is biased towards the upper bound of the ensemble dataset.

To finalize the correlations for flight support and remove any unnecessary conservatism, the decision was made to adjust the best fit and bounds of the ensemble dataset to coincide with the mean of the flight cases, as shown in Fig. 10. The rationale for this adjustment is that the flight trend is best represented by the mean of the historical flight cases, while the experimental scatter, which accounts for the effects of different types and orientations of protuberances, is captured by the bounds of the ensemble dataset. Note that the adjusted bounds also provide a good capture of the flight uncertainty bars. In some sense, this adjustment to the correlations is philosophically aligned with the posture adopted with V1 where the flight cases were a strong anchor to the final correlation. It is important to note, however, that this is a modification to the recommendations included in the final Peer Review Report, which stated: "the panel recommends that flight and ground data be weighted equally, and that the correlations be based on the entire data set". After careful consideration of tool implementation by the development team and based on experience from flight support operations, it was decided that this adjustment to the mean and combined flight and wind tunnel data uncertainty would provide the most appropriate result. The correlations are still based on the entire data set, however the flight calibration cases have been used to adjust the mean, thus allowing the prediction accuracy for $\mathrm{V} 2$ to be better than the previous version.

For completeness, Fig. 11 shows the final adjusted protuberance correlation curves in relation to all the experimental data. Similar to V1, some of the experimental data now falls below what is considered the conservative bound for the transition estimate. The difference this time is that all of the data was used to define the outer bounds of the correlation uncertainty, with the flight calibration cases providing the final adjustment for the best estimate. Table 1 provides a comparison of the predicted BLT onset from this final adjusted correlation for $\mathrm{V} 2$ in comparison to results from V1 for the historical flight cases. Further details on the V2 protuberance correlation development are given in Ref. 38.

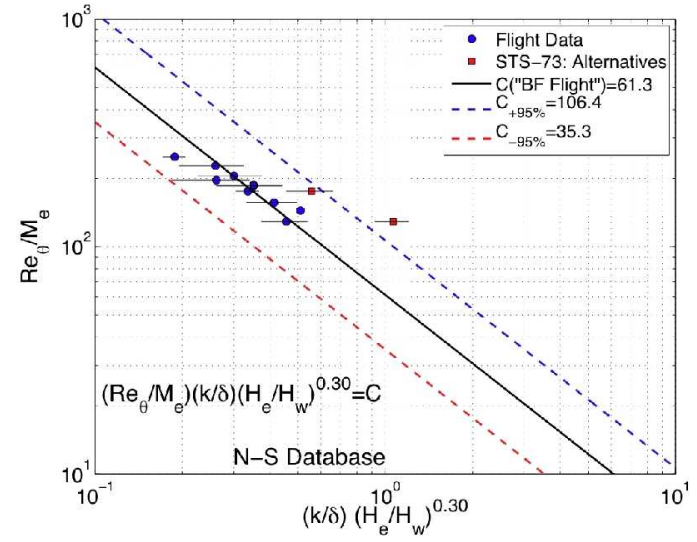

a) $\operatorname{Re}_{\theta} M_{\mathrm{e}}$ correlation

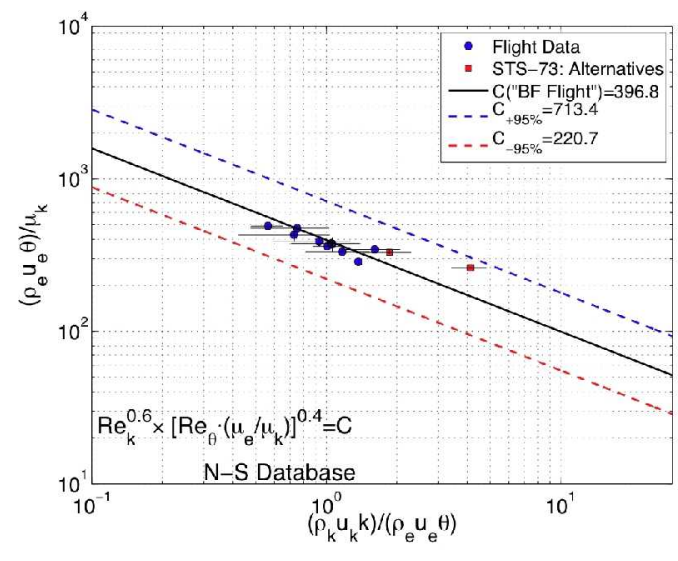

b) $R e_{k}$ correlation

Figure 10. Flight uncertainties in relation to bounds of the data adjusted to match flight 

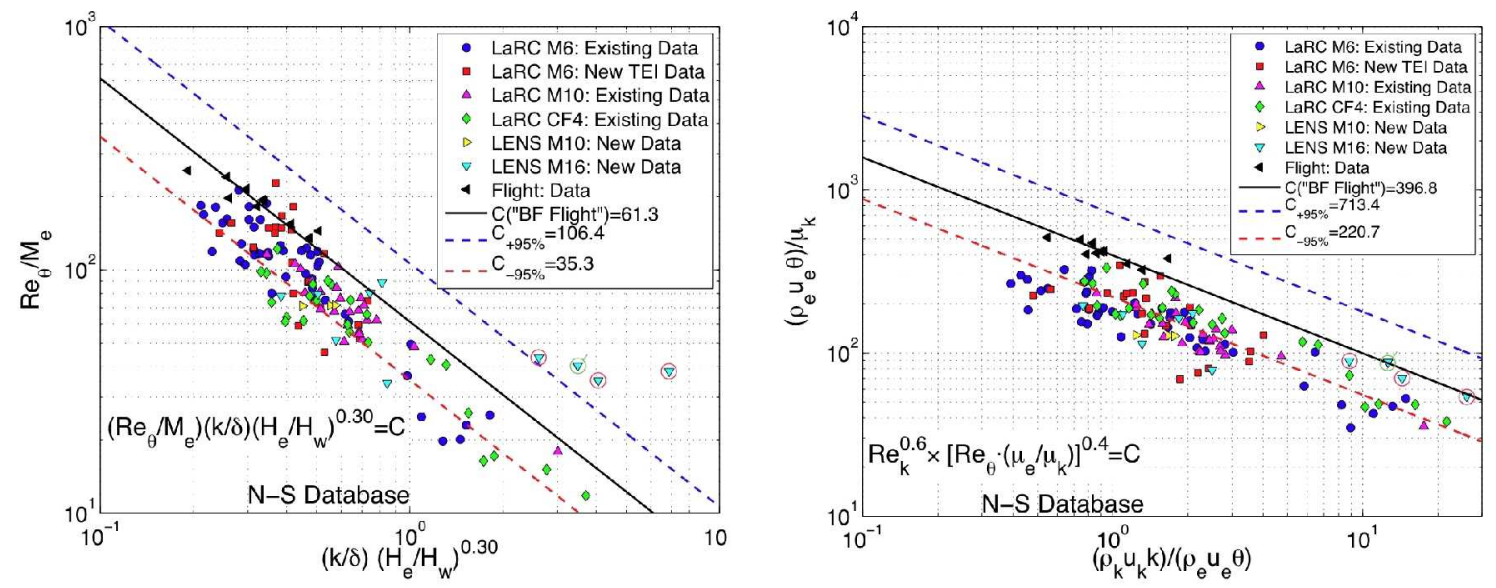

a) $\operatorname{Re}_{\theta} / M_{e}$ correlation

b) $\operatorname{Re}_{\mathrm{k}}$ correlation

Figure 11. Final protuberance correlations recommended for BLT Tool V2

Table 1. Historical data, V.1 protuberance prediction, and V.2 protuberance prediction comparison

\begin{tabular}{|c|c|c|c|c|c|c|c|c|c|c|c|}
\hline \multirow[b]{2}{*}{ Flight } & \multirow[b]{2}{*}{ Gap Filler $^{a}$} & \multirow[b]{2}{*}{$k(\text { in. })^{b}$} & \multirow[b]{2}{*}{$\begin{array}{c}\text { Transition } \\
\text { time }(\mathrm{s})\end{array}$} & \multicolumn{6}{|c|}{ V.2 Prediction (s) } & \multicolumn{2}{|c|}{ V.1 Prediction (s) } \\
\hline & & & & $\begin{array}{l}\text { Edged } \\
(-95 \%)\end{array}$ & $\begin{array}{c}\text { Based } \\
\text { (BE) }\end{array}$ & $\begin{array}{l}\text { Method } \\
(+95 \%)\end{array}$ & $(-95 \%)$ & $\begin{array}{l}\text { e-metl } \\
\text { (BE) }\end{array}$ & $\begin{array}{l}\text { od } \\
(+95 \%)\end{array}$ & $\mathrm{C}=27$ & $\mathrm{C}=33$ \\
\hline STS-28 & $\mathrm{A}-28$ & 0.50 & 902 & 773 & 892 & 982 & 738 & 914 & 1065 & 863 & 903 \\
\hline STS-28 & B-28 & 0.50 & 912 & 766 & 888 & 974 & 720 & 892 & 997 & 827 & 884 \\
\hline STS-41 & $\mathrm{C}-41$ & 0.11 & 1201 & 1109 & 1254 & $>1262$ & 969 & 1229 & $>1262$ & 1176 & 1206 \\
\hline STS-55 & A-55 & 0.20 & 1060 & 969 & 1064 & 1252 & 926 & 1056 & 1285 & 1029 & 1065 \\
\hline STS-55 & $\mathrm{C}-55$ & 0.20 & 1060 & 961 & 1057 & 1243 & 941 & 1073 & 1295 & 1032 & 1060 \\
\hline STS-73 & A-73 & 0.60 & 880 & 752 & 889 & 999 & 718 & 911 & 1062 & 85.5 & 909 \\
\hline STS-81 & A- 81 & 0.32 & 966 & 878 & 971 & 1115 & 839 & 981 & 1249 & 953 & 981 \\
\hline STS-94 & A-94 & 0.30 & 993 & 885 & 981 & 1106 & 855 & 1000 & 1253 & 972 & 996 \\
\hline STS-99 & A-99 & 0.35 & 1012 & 902 & 1004 & 1115 & 847 & 1015 & 1247 & 993 & 1016 \\
\hline STS-103 & A-103 & 0.25 & 958 & 897 & 984 & 1191 & 857 & 973 & 1227 & 958 & 983 \\
\hline STS-121 & rpm700-3 & 0.4 & 938 & 747 & 872 & 990 & $<700$ & 838 & 969 & 811 & 847 \\
\hline
\end{tabular}

${ }^{a}$ See EG-SS-07-09 for more information

${ }^{b}$ Nominal reported protuberance heights listed

To illustrate how the best-fit correlation and upper/lower confidence bounds relate to BLT prediction uncertainty, plots are provided next of a typical flight case in V2 correlation space for a representative location and height on the vehicle. Figure 12 provides both correlations plotted against a representative historical flight case using STS-94, which is also listed in Table 1. The measured transition time for STS-94 was 993 seconds, while Fig. 12 shows that the V2 "best estimate" transition prediction is $981 \mathrm{~s}$ and $1000 \mathrm{~s}$ for the primary $\left(\mathrm{Re}_{\mathrm{g}} / \mathrm{M}_{\mathrm{e}}\right)$ and secondary $\left(\mathrm{Re}_{\mathrm{k}}\right)$ correlation approaches, respectively. In this case, the primary prediction is slightly conservative in comparison to the measured onset time, while the secondary is not. Also, the bounding uncertainty based on $\pm 95 \%$ confidence levels of the experimental data provides a conservative and upper bound prediction of $885 \mathrm{~s}$ and $1106 \mathrm{~s}$ for the primary approach and $855 \mathrm{~s}$ and $1253 \mathrm{~s}$ for the secondary approach, respectively. The $\mathrm{Re}_{a} / \mathrm{Me}_{\mathrm{e}}$ correlation has a smaller uncertainty band around the best estimate than the $\mathrm{Re}_{k}$ approach. Table 1 provides a comparison for all the historical cases with both V2 correlations (as well as the results from V1), indicating the trends discussed above with the STS-94 example case generally hold true. The best estimate for the $\mathrm{Re}_{\mathrm{\theta}} / \mathrm{M}_{\mathrm{e}}$ correlation appears to be slightly more conservative than with the $\mathrm{Re}_{\mathrm{k}}$ correlation approach. In addition, the uncertainty band for the $\mathrm{Re}_{0} / \mathrm{M}_{\mathrm{e}}$ correlation is smaller than the uncertainty band for the $\mathrm{Re}_{\mathrm{k}}$ correlation. 


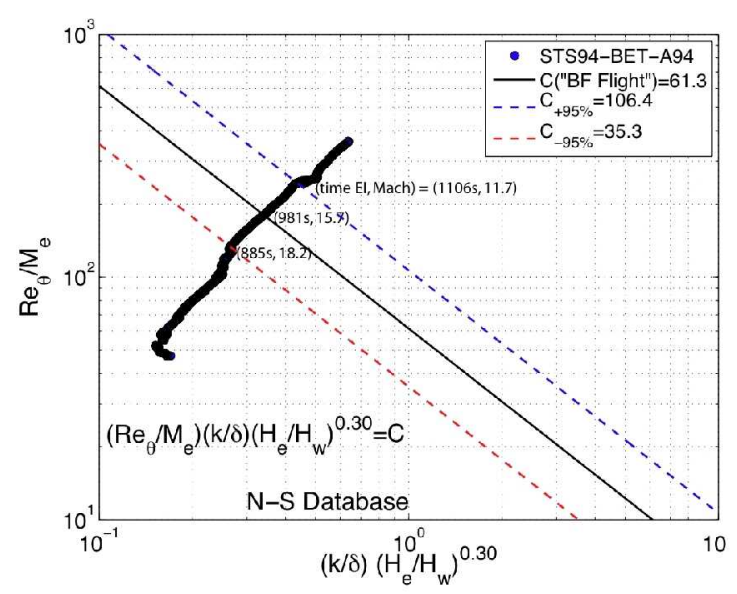

a) $\operatorname{Re}_{\theta} / M_{e}$ correlation

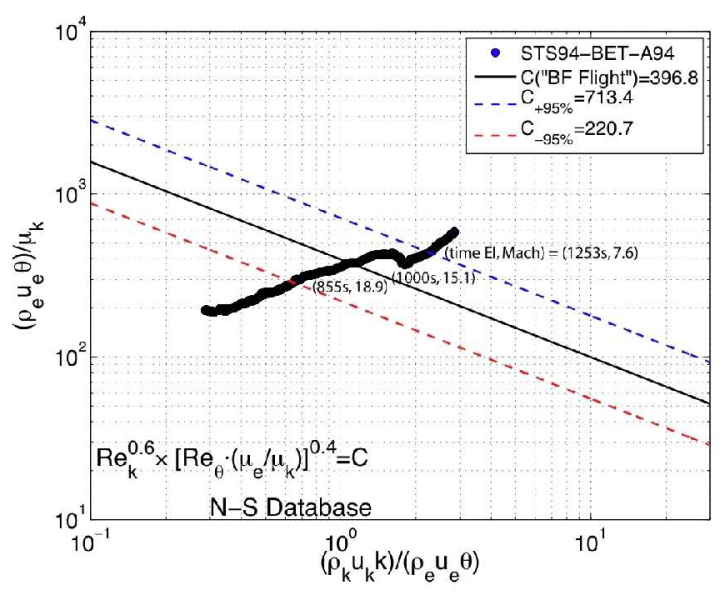

b) $\operatorname{Re}_{k}$ correlation

Figure 12. Comparison of correlation uncertainties against STS-94 gap filler case

Finally, the V2 tool was used to reinvestigate one of the early transition prediction cases from STS-114 as a way to illustrate the improvements provided by the update. Figure 13 provides the V2 BLT onset predictions for gap filler 134-01 of STS-114 using both correlation approaches in comparison to the initial result obtained from V1. The height required to force BLT onset based on the local properties at the roughness site is plotted as a function of the trajectory time in both plots. The estimated height of 1.1-in, along with the protuberance measurement height uncertainty of \pm 0.3 -in is used to determine the BLT time predictions. The $\mathrm{Re}_{\mathrm{g}} / \mathrm{M}_{\mathrm{e}}$ correlation based on edge properties provides a best estimate BLT onset prediction of $668 \mathrm{~s}$ with uncertainty bounds (based on tool uncertainty only) of $480 \mathrm{~s}$ and $826 \mathrm{~s}$ for the conservative and upper bound correlations, respectively. The corresponding BLT onset prediction utilizing the $\mathrm{Re}_{\mathrm{k}}$ correlation (based on properties within the boundary layer) provides a best estimate of $837 \mathrm{~s}$ with uncertainty bounds of $529 \mathrm{~s}$ and 970 s for the conservative and upper bound correlations, respectively. These results are in comparison to the initial V1 prediction of $450 \mathrm{~s}$ (shown) and the final adjusted prediction time of $745 \mathrm{~s}$ (see Ref. 3 ). It is interesting to note that within the calibration range of Mach 6 to 18 from flight history (roughly times after 900s), the V1 results are in fairly close agreement with the best estimate $\operatorname{Re}_{\theta} / M_{e}$ results from V2, while at the higher Mach numbers, or lower times, the V1 results are closer to the conservative results. The point of departure between the two versions corresponds to Mach number at which the V1 database switched from LATCH to N-S solutions, which provides additional evidence as to the need for the present upgrade.

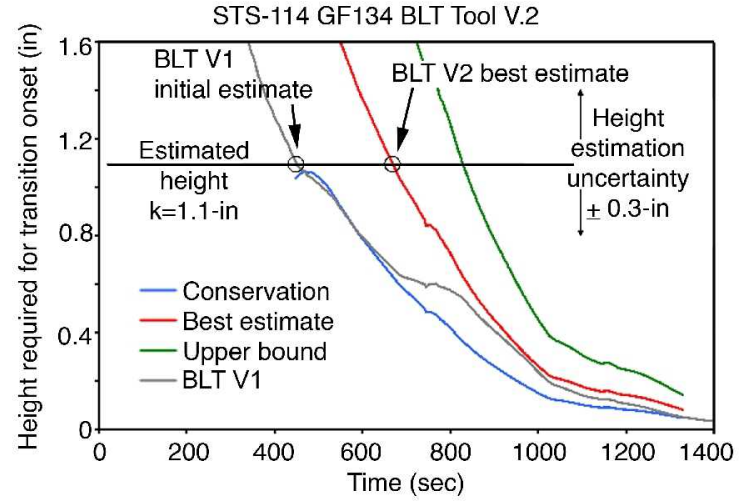

a) $\operatorname{Re}_{\theta} / M_{e}$ correlation

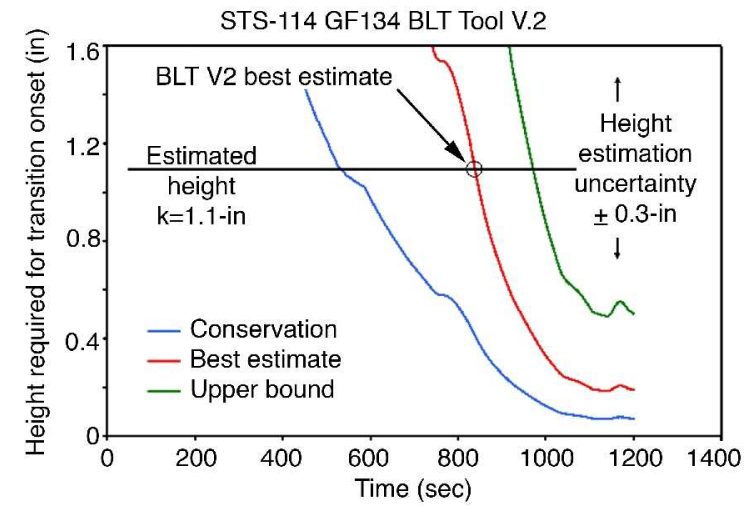

b) $R_{\mathrm{k}}$ correlation

Figure 13. Comparison of correlation prediction results for STS-114 gap filler 134 case 


\section{Cavity correlations}

Early on in the V2 development, a second look at formulating a true correlation of the cavity data was initiated and an approach was identified ${ }^{39}$ that nicely collapsed all the data, as shown in Fig. 14. The primary difference with this correlation approach was the inclusion of all cavity dimensions (length, width, and depth), and Reynolds number and temperature ratio terms in the disturbance parameter ( $x$ axis). Whereas in V1 the cavity transition onset data was widely spread above the threshold line, the V2 correlation now collapses all the data from multiple facilities (both old and new data) within a fairly tight set of $95 \%$ confidence lines. In addition, the new experimental data was an important addition to the V 2 cavity correlation development, providing a better experimental dataset with multiple locations around the windward surface, as well as various cavity shapes and orientations. Also during the V2 development, a major revision to the list of flight calibration cases for cavities occurred (as noted earlier). With the more in-depth review of the flight data, some of the cases used for V1 were determined to have small gap fillers in the vicinity of the cavity sites. These gap fillers were on the order less than 0.1 -in protrusions and were not considered large for reporting purposes but nevertheless might also have been responsible for the measured transition times. Thus, for the V2 effort only three cavity cases were utilized, as shown in Fig. 14 and listed in Table 2 . Since there were only three lower confidence cavity flight calibration cases, the final correlation was not adjusted to match flight.

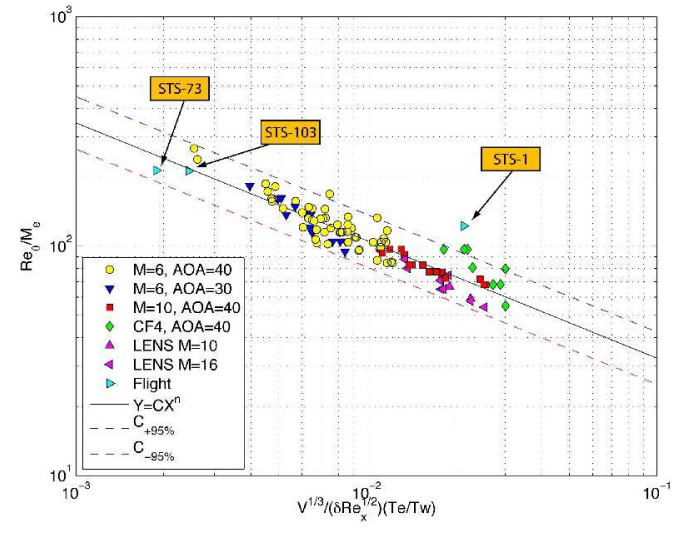

Figure 14. Cavity volume-based correlation for BLT Tool V2

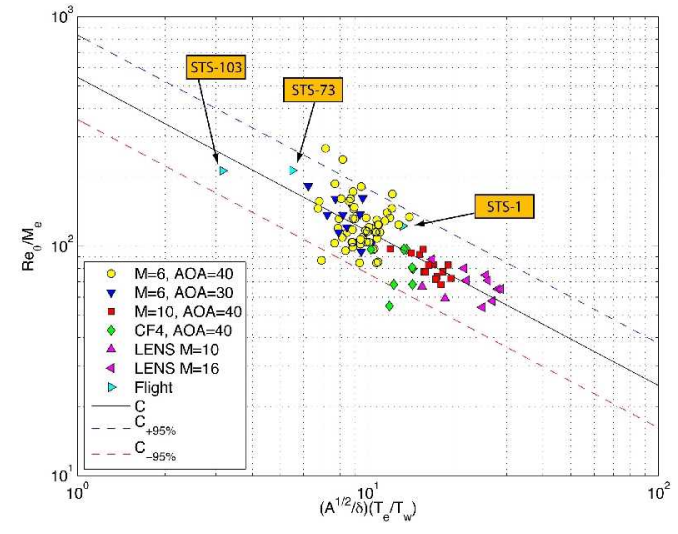

Figure 15. Cavity area-based correlation for BLTTool V2

Table 2. Historical BLT data, V.1 cavity prediction, and V.2 cavity prediction comparison

\begin{tabular}{|c|c|c|c|c|c|c|c|c|c|c|c|}
\hline \multirow[b]{2}{*}{ Flight } & \multirow[b]{2}{*}{ Cavity $^{b}$} & \multirow[b]{2}{*}{$L, W, D$ (in.) } & \multirow[b]{2}{*}{$\begin{array}{c}\text { Transition } \\
\text { time (s) }\end{array}$} & \multicolumn{6}{|c|}{ V.2 Prediction (s) } & \multicolumn{2}{|c|}{ V.1 Prediction (s) } \\
\hline & & & & $(-95 \%)$ & $\begin{array}{c}\text { Volume }^{a} \\
\text { (BE) }\end{array}$ & $(+95 \%)$ & $(-95 \%)$ & $\begin{array}{l}\text { Area } \\
\text { (BE) }\end{array}$ & $(+95 \%)$ & $\begin{array}{l}\text { Depth } \\
\mathrm{C}=100\end{array}$ & $\begin{array}{l}\text { Length } \\
\mathrm{C}=900\end{array}$ \\
\hline STS-1 & B-1 & $10.0,0.7,1.0$ & $<1050$ & 597 & 797 & 909 & 853 & 972 & 1087 & 996 & 974 \\
\hline STS-73 & G-73 & $2.3,0.8,0.4$ & 1167 & 1076 & 1278 & $>1356$ & 970 & 1075 & 1276 & 1121 & 1247 \\
\hline STS-103 & B-103 & $1.0,0.5,0.2$ & 1156 & 953 & 1162 & $>1280$ & 996 & 1248 & $>1280$ & 1269 & 1366 \\
\hline STS-114 & rpm942-1 & $0.8,2.1,0.3$ & 1250 & 881 & 975 & 1130 & 933 & 1034 & 1287 & 1250 & 1451 \\
\hline
\end{tabular}

${ }^{a}$ Cavity volumes calculated using a conservative "shoebox" ( $\left.L x W x D\right)$ approach

${ }^{b}$ See EG-SS-07-09 for more information

As a response to specific recommendation from the peer review group, Fig. 15 illustrates a correlation based on the surface area of the damage site. This correlation may be useful as an initial screening tool before any depth information is obtained via a focused inspection. Note however that the experimental scatter bounds for the data are much larger than the scatter bounds for the volume approach. Results for the area correlation may need to be compared against the volume-based approach using a parametric range of depths. It is interesting to note that although the higher percentages of actual damage sites tracked throughout the history of the Shuttle program are cavities, by far, the predominance of the early BLT cases are due primarily to protruding gap fillers. 


\section{Recent wing leading edge correlation}

Even with the improvements provided by the migration to BLT Tool V2, there was still one additional area of concern that first became evident during STS-114 and periodically came up during subsequent missions. When BLT was predicted to occur at high Mach numbers on the forebody region ahead of the wing leading edge (WLE), the resulting aeroheating environments provided a severe challenge to the subsequent thermal and stress analysis on the RCC panels. The inability of the Orbiter project to get comfortable with the impact of very early BLT along the WLE during STS-114 was ultimately the reason for the decision to attempt an unplanned and potentially risky repair by removal of the protruding gap fillers. After a couple problematic missions, a review was conducted of the pertinent flight data. The review was limited to flights during which a radiometer was used within the port wing of Space Shuttle Discovery or Columbia (other vehicles and wings were not instrumented with the radiometer).

The earliest case for which it was determined that a turbulent wedge did influence the port WLE (as determined by examining thermocouple data immediately forward and aft of the WLE) was found to be STS-48. As shown in Fig. 16, the thermocouples on the port side, just forward of the wing and just behind the WLE indicate that the boundary layer transitioned to a turbulent state at $1005 \mathrm{sec}$. The radiometer, measuring the backside temperature at RCC Panel 9 , indicated boundary layer transition at $1010 \mathrm{sec}$ (see Fig. 17), only 5 seconds later. These times correspond to a Mach number of approximately 13.7 and this is the earliest measured case of BLT along the WLE.

Subsequently, a review of existing ground-base data from the perspective of supporting a new WLE BLT assessment process was conducted. The approach proposed was based on an existing attachment line correlation developed by Poll ${ }^{19}$ (see also Ref. 42) called R-bar and the ground-based data used to support its use for the Shuttle is detailed in a report by King and Vaughan. ${ }^{40}$ Supporting computations for this analysis are provided in Ref. 43. The existing WLE ground-based data, obtained during the $\mathrm{MH}-$ 13 test in CUBRC, and the new analysis suggested that turbulence cannot be sustained along the WLE unless the local conditions exceed a R-bar threshold limit of roughly 245 , which supports Poll's earlier results. The limited number of flight cases available, listed in Table 3, also supports this threshold, although these flight data correspond to cases where BLT on the WLE is at approximately the same time on the windward surface. Figure 17 provides the calculated R-bar value for STS-48 of 281. Other cases identified are shown in Table 3 though all have later BLT and R-bar values greater than that of STS-48. The STS-114 case is included to represent a nominal BLT time (since the large gap fillers had been removed) for comparison. Other cases of early BLT on the WLE were identified but on the starboard wing and/or vehicles without a radiometer and thus WLE BLT onset times

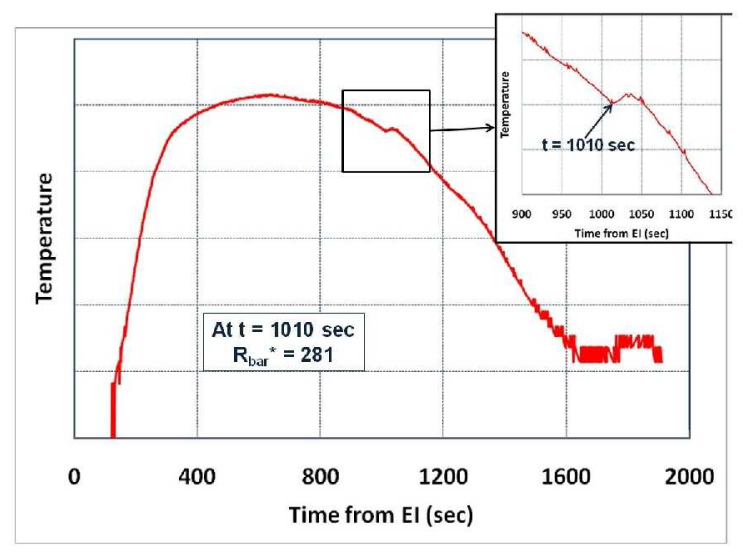

Figure 17. Wing leading edge data on STS-48 
cannot be determined. A separate peer review on this approach for the WLE was recently completed. As this methodology is mainly intended to provide additional guidance with delayed turbulence along the WLE, a conservative value of 200 will be used for panels 8 and 9 as the initial threshold for use in the RCC thermal and stress analysis. This value was selected to be below both tunnel and flight results due to the limited number of cases identified.

Table 3. Flight WLE BLT results

\begin{tabular}{|c|c|c|c|c|}
\hline \multirow{2}{*}{ Flight } & \multicolumn{2}{|c|}{ Port Thermocouple BLT } & Radiometer & \multirow{2}{*}{ R-bar } \\
\cline { 2 - 4 } & Times (sec) & Mach Number & Time (sec) & \\
\hline STS-48 & 1005 & 13.7 & 1010 & 281 \\
\hline STS-56 & $1125-1225$ & $10.2-7.5$ & 1250 & 401 \\
\hline STS-102 & $1065-1075$ & $12.7-12.4$ & 1080 & 307 \\
\hline STS-114 & $1230-1269$ & $7.9-7.0$ & 1275 & 431 \\
\hline
\end{tabular}

\section{Recent flight results}

As mentioned earlier, STS-114 provided notice in regards to the limits of many of the tools available for DAT analysis. Foremost in that group, the BLT Tool needed significant improvement to enhance the applicability range of the correlation and reduce uncertainties with use of the tool at extrapolated conditions. Ultimately, the uncertainty associated with the BLT predictions and entry aerothermodynamics together with potential effects upon the high heating shock-shock interaction region of the wing leading edge led to a decision by the STS-114 MMT to remove the two protruding gap fillers. ${ }^{3}$ Thankfully, this first ever Shuttle repair was performed without incident and the gap fillers were removed without incurring any other damage to the TPS. As one might suspect, sending an astronaut to perform in close proximity to the Orbiter TPS is not something to be taken lightly. As a result of those events during STS-114, significant progress was made in proposing the utilization of Orbiters as a flight test vehicle. This dialogue led to a proposal to conduct Orbiter entry flight-testing for acquisition of hypersonic, high enthalpy aerothermodynamic data. ${ }^{8}$ The proposal included a flight experiment on boundary layer transition from a protuberance, to be carried out in a region on the port wing with plenty of structural and thermal margin. Ultimately, the BLT flight experiment (FE) was approved for a series of flights using a fixed geometry protuberance that would systematically increase in height with each mission. Two of these missions have thus far been successfully flown and Anderson, et $\mathrm{al}^{9}$ will provide details of those missions (STS-119 and 128) and the results of the experiments. Additionally, airborne imaging systems were utilized to view the Orbiter during both entries in both visual and IR spectra as part of the HYTHIRM imaging campaign. ${ }^{10}$

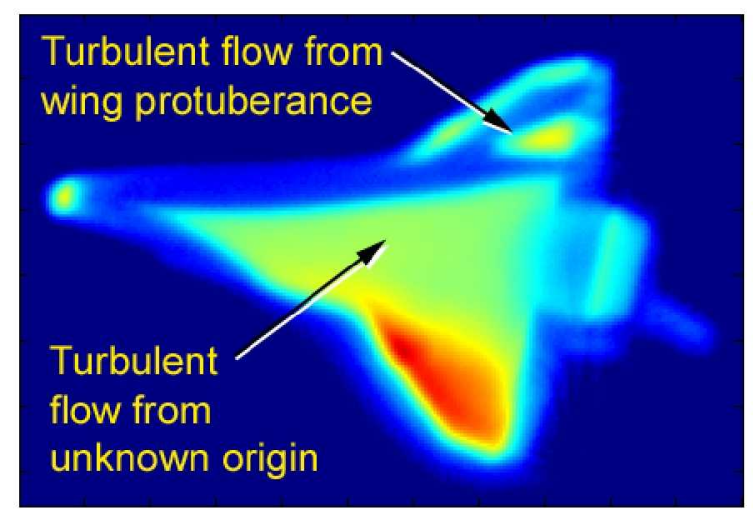

Figure 18. HYTHIRM image from STS-119

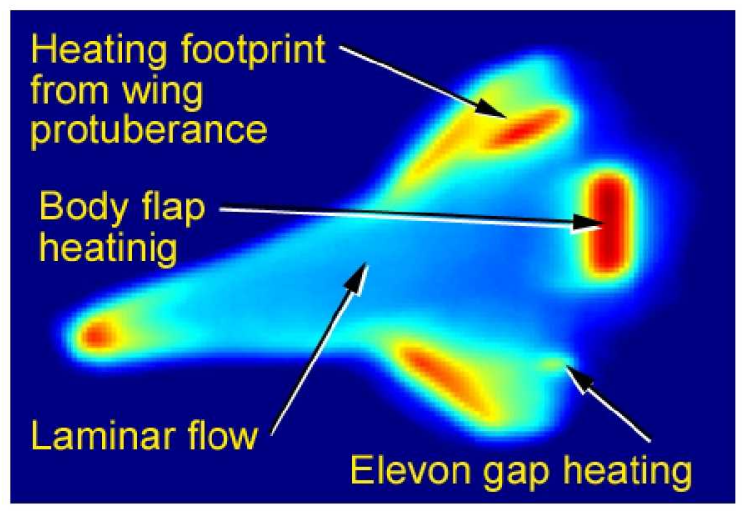

Figure 19. HYTHIRM image from STS-128

STS-119 was the first BLT FE mission flown in March 2009 with 0.25 -in high trip that was designed to resemble a protruding gap filler. Based on that fixed height (verified post flight) and the as-flown trajectory, the BLT Tool prediction using the $\mathrm{Re}_{\theta} / \mathrm{Me}_{\mathrm{e}}$ best estimate correlation was for transition onset at Mach 15.4. The measured results showed onset at the aft-most thermocouple at a Mach number of 15.6. The prediction was slightly un-conservative but well within the 2-sigma uncertainty band for the 
tool. Figure 18 provides an IR image from reentry provided by the HYTHIRM team. This image was acquired at Mach 8.4, a lower Mach number than the designed BLT onset point for the FE. The port side turbulent wedge from the FE is seen in the upper part of the image, while the lower side shows a second turbulent wedge emanating from an unknown source. Since this image was taken close to time of nominal transition, this second large wedge is likely from a very small step or gap in the region of the nose landing gear door.

STS-128 was the second BLT FE mission flown in September 2009 with 0.35 -in high trip of similar shape that was sized specifically to provide transition onset near Mach 18, the historical flight limit. The best estimate prediction based on the as-flown trajectory was BLT onset at Mach 17.4, with a measured result of 17.5, again slightly un-conservative but well within the 2-sigma uncertainty band for the tool. Figure 19 provides an IR image from reentry provided by the HYTHIRM team. This image corresponds to Mach 14.7, a little closer to the design BLT onset point. At this higher Mach number, the nose and upper wing leading edge (both laminar) can be seen to be at much higher temperatures than shown in the previous figure. The body flap is deflected down 7.5-deg into the flow at this point in the trajectory, which explains the high temperatures at the end of the vehicle. For the $\mathrm{FE}$, the turbulent wedge on the port side is seen in the upper part of the image and since the Mach number is much higher, the rest of the windward surface is laminar.

In regards to other recent missions, the BLT Tool V2 has been used on all since STS- 117 with excellent agreement shown via post flight analysis. There were several relatively clean missions, such as STS-123, 125 , and 126, which all had late or nominal transition during reentry. There have been a couple of missions in which thermal barriers around the external tank attachment point near the nose landing gear door have protruded slightly, which has led to slightly earlier BLT. STS-116 is one example with a measured onset of Mach 13.5. The post flight measurement of this 0.2 -in protrusion corresponds to a BLT V2 best estimate prediction of 12.9. There are other missions with similar agreement between post flight prediction and measurement.

\section{Summary}

The Boundary Layer Transition Tool developed for Shuttle mission support has been upgraded to improve the confidence associated with the predicted results. Enhancements to the experimental, computational, and flight databases have led to a capability that has been instrumental in allowing informed decisions during on-orbit mission support. The experimental data for both protuberances and cavities have been enhanced via new wind tunnel entries that provided a wider parametric variation in trip geometries, locations, orientations, and Mach numbers. The computational database used to derive the correlations at wind tunnel conditions and then apply to flight conditions has been replaced with new higher fidelity computational solutions. A new review of the historical flight data has allowed for an uncertainty assessment of the final flight correlations. These results have allowed for Version 2 of the BLT Tool, which has subsequently been used to design a flight experiment to obtain controlled protuberance boundary layer transition data. The results from the first two flights with the experiment installed on the port wing have provided validation of the BLT Tool V2 Tool used to design the trips.

\section{Acknowledgements}

The authors would like to thank the Peer Review Committee for their support during the development of BLT Tool V2: Sun Hong of The Boeing Company, Roger Kimmel from Air Force Research Laboratory, Anthony Martellucci formerly of the Science Application International Corporation (retired), John Schmisseur from Air Force Research Laboratory, Vince Zoby of NASA Langley Research Center, and the committee chair, David Kuntz of Sandia National Laboratories. 


\section{References}

1 Columbia Accident Investigation Board Final Reports, Vols. I-VI [online resource], URL: http://caib.nasa.gov/ [cited Aug and Oct 2003].

2 Campbell, C., Anderson, B., Bourland, G., Bouslog, S., Cassady, A., Horvath, T., Berry, S., Gnoffo, P., Wood, B., Reuther, J., Driver, D., Chao, D., and Picetti, D., “Orbiter Return To Flight Entry Aeroheating," AIAA-2006-2917, June 2006.

3 Berry, S. A., Horvath, T. J., Cassady, A., Kirk, B. S., Wang, K.C., and Hyatt, A. J., "Boundary Layer Transition Results From STS-114," AIAA-2006-2922, San Francisco, CA, June 2006.

4 Berry, S. A., Horvath, T. J., Greene, F. A., Kinder, G. R., and Wang, K. C., “Overview of Boundary Layer Transition Research in Support of Orbiter Return To Flight," AIAA-2006-2918, June 2006.

5 Horvath, T. J., Berry, S. A., Merski, N. R., Berger, K. T., Buck, G. M., Leichty, D. S., and Schneider, S. P., “Shuttle Damage/Repair from the Perspective of Hypersonic Boundary Layer Transition - Experimental Results," AIAA2006-2919, June 2006.

6 Greene, F. A., Hamilton, H. H., “Development of a Boundary Layer Properties Interpolation Tool in Support of Orbiter Return to Flight," AIAA Paper -2006-2920, June 2006.

7 McGinley, C. B., Berry, S. A., Kinder, G. R., Barnwell, M., Wang, K. C., Kirk, B. S., “Review of Orbiter Flight Boundary Layer Transition Data," AIAA-2006-2921, San Francisco, CA, June 2006.

8 Campbell, C. H., Garske, M. T., Kinder, G. R., and Berry, S. A., "Orbiter Entry Boundary Layer Flight Testing," AIAA Paper 2008-0635, Jan. 2008.

9 Anderson, B.P., Campbell, C.H., Saucedo, L.A., Kinder, G.R., "BLT Flight Experiment Overview and In-Situ Measurements," AIAA 2010-0240, January 2010.

10 Horvath, T. J. Tomek, D. M. Berger, K. T., Zalameda, J. N., Splinter, S. C., Krasa, P. W., Schwartz, R. J., Gibson, D. M., Tietjen, A. B., and Tack, S., "The HYTHIRM Project: Flight Thermography of the Space Shuttle during Hypersonic Re-entry," AIAA Paper 2010-0241, Jan. 2010.

11 Berry, S. A.; Bouslog, S. A.; Brauckmann, G. J.; and Caram, J. M.: "Shuttle Orbiter Experimental Boundary-Layer Transition Results with Isolated Roughness," Journal of Spacecraft and Rockets, Vol. 35, No. 3, 1998, pp. 241-248.

12 Berry, S. A.; Horvath, T. J.; Hollis, B. R.; Thompson, R. A.; and Hamilton, H. H.: "X-33 Hypersonic Boundary Layer Transition," Journal of Spacecraft and Rockets, Vol. 38, No. 5, 2001, pp. 646-657.

13 Berry, S. A., Hamilton, H. H., and Wurster, K. E., "Effect of Computational Method on Discrete Roughness Correlations for Shuttle Orbiter," Journal of Spacecraft and Rockets, Vol. 43 No. 4, 2006, pp. 842-852.

14 Hamilton, H. H., Greene, F. A.m and DeJarnette, F.R., "Approxiame Method for Calculating Heating Rates on Three-Dimensional Vehicles," JSR Vol. 31, No. 3, pp. 345-354, 1994.

15 Wurster, K. E., Riley, C. J., and Zoby, E. V., “Engineering Aerothermal Analysis for X-334 Thermal Protection System Design," JSR vol.36 no.2, pp. 216-228, 1999.

16 Amar, A., Horvath, T., Hollis, B., Berger, K., Berry, S., and N. Calvert, "Protuberance Boundary Layer Transition for Project Orion Crew Entry Vehicle," AIAA-2008-1227, Jan. 2008.

17 Lee, D. B. and Harthun, M. H., "Aerothermodynamic Entry Environment of the Space Shuttle Orbiter," AIAA Paper 82-0821, June 1982.

18 Goodrich, W. D., Derry, S. M., and Bertin, J. J., "Shuttle Boundary-Layer Transition: A Comparison of Flight and Wind Tunnel Data," AIAA Paper 83-0485, Reno, NV, January 1983.

19 Poll, D. I. A., "Boundary Layer Transition on the Windward Face of the Space Shuttle During Re-Entry," AIAA Paper 85-0899, June 19985.

20 Hartung, L. C., Throckmorton, D. A., "Computer Graphic Visualization of Orbiter Lower Surface Boundary-Layer Transition," JSR vol.24 no.2, pp. 109-114, 1987.

21 Bouslog, S. A., An, M. Y., Hartmann, L. N., Derry, S. M., “Review of boundary layer transition flight data on the Space Shuttle Orbiter," AIAA-1991-741, Reno, NV, Jan 1991.

22 Bouslog, S. A., Bertin, J. J., Berry, S. A., and Caram, J. M., "Isolated Roughness Induced Boundary Layer Transition: Shuttle Orbiter Ground Tests and Flight Experience," AIAA Paper 97-0274, Jan. 1997.

23 Berry, S. A. and Horvath, T. J., “Discrete-Roughness Transition for Hypersonic Flight Vehicles," Journal of Spacecraft and Rockets, Vol. 45 No. 2, pp. 216-227, 2008. 
24 Berry, S., Horvath, T., Schwartz, R., Ross, M., Anderson, B., and Campbell, C., "Infrared Imaging of Boundary Layer Transition Flight Experiments," AIAA-2008-4026, Seattle, WA, June, 2008.

25 Miller, C. G., "Langley Hypersonic Aerodynamic/Aerothermodynamic Testing Capabilities - Present and Future," AIAA Paper 90-1376, 1990.

26 Micol, J. R., "Langley Aerothermodynamic Facilities Complex: Enhancements and Testing Capabilities," AIAA Paper 98-0147, Jan. 1998.

27 Wadhams, T.P., Smolinski, G. J., Holden, M. S., and MacLean, M. G., “Experimental Space Shuttle Orbiter Studies to Acquire Data for Code and Flight Heating Model Validation," AIAA Paper 2007-0551, Jan. 2007.

28 CUBRC Research Staff, "Large Energy National Shock Tunnel (LENS) Description and Capabilities Rev.3", CUBRC, Buffalo, NY, April 2009.

29 William A. Wood, David W. Erickson and Francis A. Greene, "Orbiter Entry Aeroheating Working Group Viscous CFD Boundary Layer Transition Trailblazer Solutions," NASA/TM 2007-214882, Jul. 2007.

30 Alter, S. J. and Wood, W. A., "A Database of Space Shuttle Orbiter Computational Fluid Dynamics Solutions at Wind Tunnel Conditions," JSC Engineering Note EG-SS-07-13, Jeb. 2007.

31 Meyer, B., "Boundary Layer Probing and Reynolds Number Interpolation Tool: Blvolprops v3.0," LaRC Hypersonic Vehicle Analysis Group Technical Note 06-488, Nov. 2006.

32 Hyatt, A.J., Wang, K.C., Everhart, J.L., Green, F.A., Merski, N.R., Wood, W.A., Berger, K., Anderson, B.P., Cassady, A.C. "The Cavity Heating Tool Version 3.0 Documentation", Technical Memorandum, ATA-AH-TM-2006-035, The Boeing Company, October 10, 2006.

33 Bill Wood, "Viscous-CFD Space Shuttle Orbiter boundary layer data and probe software," JSC Engineering Note EG-SS-07-10

34 Alireza Mazaheri, "Flight Boundary Layer Tool for Volume and Surface Probe (FBLT-VASP)," JSC Engineering Note EG-SS-07-12

35 McGinley, C. B., "Orbiter Historical Flight Boundary Layer Transition," JSC Engineering Note EG-SS-07-09, 2007.

36 Berry, S. A., "Boundary Layer Transition Tool V.2 Overview and Verification," JSC Engineering Note EG-SS-07-15 Version 2, May 2009.

37 Bill Wood, "Requirement verification for viscous-CFD Space Shuttle Orbiter boundary layer data and probe software," JSC Engineering Note EG-SS-07-11, 2007.

38 King, R. A., Kegerise, M. A., Berry, S. A., "Version 2 of the Protuberance Correlations for the Shuttle Boundary Layer Transition Tool," NASA TP-2009- 215951, Dec. 2009.

39 Mike Kegerise, "Development of Cavity Induced Boundary Layer Transition Correlations for Version 2 of the BLT tool," JSC Engineering Note EG-SS-07-05, 2007.

40 King, R. A. and Vaughan, M. P., "Turbulent Wing-Leading-Edge Correlation Assessment for the Shuttle Orbiter," NASA TM-2009-215949, Dec. 2009.

41 Reda, D. C., "Review and Synthesis of Roughness-Dominated Transition Correlations for Reentry Applications," Journal of Spacecraft and Rockets, Vol. 39, No. 2, 2002, pp. 161-167.

42 Poll, D. I. A., "The development of intermittent turbulence on a swept attachment line including the effects of compressibility," Aero Quarterly, Vol.34, pp.1-23, 1983.

43 Jose F. Padilla and William A. Wood, "Calculation of Attachment Line Reynolds Number From Orbiter CFD Solution," NASA/TM 2009-215762, Jun. 2009. 